\title{
The Development of Civility in Taiwan
}

\author{
David C. Schak
}

$\mathrm{O}$ n 18 May 1963 a letter reportedly written by a foreign student appeared in the Central Daily News, the Kuomintang (KMT) newspaper. According to the letter writer, renqingwei, translated as "the human touch," and referring to the treatment of acquaintances with consideration and generosity, was found in abundance in Taiwan, but the Chinese were highly deficient in gondexin, which means "public morality." Within two days, the article had provoked a self-awareness campaign at National Taiwan University, calling on students "to engage in self-examination, build up a sense of public morality and carry out their responsibility to the nation." 3 Other universities quickly engaged in similar campaigns against this lack of public morality, which included failing to queue, disregarding traffic laws, littering, spitting and urinating in public, being impolite to strangers, smoking where prohibited, being noisy at night, heedlessly inconveniencing others, and not respecting public property. Little resulted from these efforts, however. Like many other top-down initiatives during the pre-democratization period, people paid scant attention to this one, knowing that such campaigns would be sporadically enforced at best, quickly wound up, and then forgotten. ${ }^{4}$

Nevertheless, changes began to appear in the 1990s as the previously authoritarian government gave way to democratization, and a strong civil society developed. Over the past two decades there has been a profoundly significant change in public sphere deportment, in how people treat the physical public sphere and persons encountered in it, particularly strangers.

\footnotetext{
1 Thanks to the many who have heard or read versions of this article. Special mention goes to Chang Mau-kuei, Chiu Hei-yuan, Marc Moskowitz, John R. Shepherd, Martin Griffiths, Wayne Hudson, Bruce Jacobs, Joe R. Allen and Arif Dirlik. Thanks also to the Chiang Ching-kuo Foundation for grant support (RG004-P-02), the Sociology Institute, Academia Sinica, for their hospitality and to my assistant Jonie Chang.

2 Renhua Di, "Renqingwei yu Gongdexin," [The Human Touch and Public Morality], Zhongyang Ribao 18 May 1963, p. 6.

3 Ruoshui Chen, "A Preliminary Exploration into the Principle of Public Morality: The Dual Orientation of History and Theory," paper presented at the Seminar on Public Morality and Society, Sociology Institute, Academia Sinica, Nangang, Taiwan, 19-20 April 1996, p. 8.

4 See Robert P. Weller, Alternate Civilities: Democracy and Culture in China and Taiwan (Boulder and London: Westview Press, 1999), p. 45.
} 
These changes can best be described as the development of civility. Some describe civility in terms of etiquette or good manners, ${ }^{5}$ which reflects the common usage of the term. However, Calhoun sees it as a "fundamental attitude" akin to Kant's notion of respect that communicates esteem, toleration and consideration rather than mere manners or etiquette, which she describes as "a badge of class distinction." ${ }^{\prime}$ In this sense it is like Margalit's "civilized society," one "whose members do not humiliate one another."

Others equate it with civil society. ${ }^{8}$ However, civil society is structural and functional while civility reflects a particular world view and its attendant behaviour. ${ }^{9}$ That said, they are related to the extent that civility fosters social capital, in particular what Putnam calls bridging social capital $;{ }^{10}$ the more bridging social capital people have, the more likely they will be well integrated into society. Civility and bridging social capital reinforce and may be in direct proportion to each other, but they are not the same.

In its earliest uses, civility denoted an attitude subordinating the interests of individuals, groups or communities to those of society as a whole. For Becker, examining late medieval and early Enlightenment Europe, civility demonstrates commitment to the public good rather than to primordial loyalties. ${ }^{11}$ Elias claims that it developed in the age when court etiquette was aimed at disarming the warrior class, a precondition of the modern nation. ${ }^{12}$ Contemporary political philosophers similarly see civility as the mark of a good citizen and a civil virtue, as universalistic and transcending the personal in modern society. ${ }^{13}$

Much of the writing on civility over the past forty years is on its importance in maintaining liberal democracy. ${ }^{14}$ This literature associates civility with

\footnotetext{
5 Stephen L. Carter, Civility: Manners, Morals and the Etiquette of Democracy (New York: Harper Perennial, 1998); Mark Caldwell, A Short History of Rudeness: Manners, Morals, And Misbehavior in Modern America (New York: Picador, 1999).

6 Cheshire Calhoun, "The Virtue of Civility," Philosophy and Public Affairs, vol. 29, no. 3 (2000), pp. 251, 254.

7 Avishai Margalit, The Decent Society (Cambridge \& London: Harvard University Press, 1996), p. 1; see also Joan McGregor, "Civility, Civic Virtue, and Citizenship," in Christine T. Sistare, ed., Civility and Its Discontents: Essays on Civic Virtue, Toleration, and Cultural Fragmentation (Lawrence: University of Kansas Press, 2004), p. 29; Carter, Civility, p. 11.

8 For example, see most papers in Robert E. Hefner, ed., Democratic Civility: The History and Cross-Cultural Possibility of a Modern Political Ideal (New Brunswick and London: Transaction Publishers, 1998).

9 Shils sees civility as the attitude needed for civil society to exist; Edward Shils, "The Virtue of Civil Society," Government and Opposition, vol. 26, no. 4 (1991), pp. 12-13.

10 Robert D. Putnam, Bowling Alone: The Collapse and Revival of the American Community (New York: Touchstone, 2000), p. 22.

11 Marvin Becker, Civility and Society in Western Europe, 1300-1600 (Bloomington: Indiana University Press, 1988); cited in Calhoun, "Virtue of Civility," p. 252.

12 Norbert Elias, The Civilizing Process: Sociogenetic and Psychogenetic Investigations, translated by E. Jephcott, rev. ed. (UK: Blackwell, 1994); see also John Keane, Civil Society: Old Images, New Visions (Stanford: Stanford University Press, 1998), pp. 122-23.

13 Calhoun, "Virtue of Civility," p. 252.

14 Michael Walzer, "Civility and Civic Virtue in Contemporary America," Social Research, vol. 41 (1974), pp. 593-611; Edward Shils, "Civility and Civil Society," in Steven Grosby, ed. The Virtue of Civility:
} 
tolerance, and a genuine acceptance of the validity of values and political preferences different from one's own. Schonsheck defines civility's opposite, the civic vice, as rasp, "the friction or jostling of political, moral, religious and ethnic groups that is inevitable in any multicultural liberal democracy," 15 and Walzer states that political activism is at odds with civility. ${ }^{16}$ McGregor sees civility as less intense, "an ethic for relating to strangers." Civility demands that we "exhibit respect toward them," and treat them "as if they matter. ... Treating them as if they matter means that when they are in distress one ought to help them, at least if one can do so without threatening one's own life or welfare." 17

In this article, following McGregor, civility refers to the treatment of public space and of fellow citizens, especially strangers. ${ }^{18}$ Specifically it refers to public deportment which follows from individuals regarding others, including strangers, as consociates with whom they have a moral bond as fellow human beings, and people caring for public space as something in which all are stakeholders, protecting and valuing it rather than treating it as a wasteland.

The inclusion of strangers as members of the same moral universe ${ }^{19}$ is a profound change for a society emerging from traditional agrarianism to modernity. It includes the development of what Shils calls "the civil collective of self-consciousness": individuals equally regarding others as moral equivalents to themselves and equally entitled to civil treatment. Primordial qualities diminish in significance, replaced by civil qualities. ${ }^{20}$ Specific to Chinese society, it represents a major transformation from earlier characterizations of Chinese as coarse, rude and cohering only in primordial groups. ${ }^{21}$

For Taiwan society it marks the transition from provincialism to cosmopolitan nationalism, its inhabitants regarding themselves as members of the Taiwan nation in which they are citizens in a democracy rather than

Selected Essays on Liberalism, Tradition, and Civil Society (Indianapolis: Liberty Fund, 1997b), pp. 25-62; Charles R. Kesler, "Civility and Citizenship in the American Founding," in Edward Banfield, ed. Civility and Citizenship in Liberal Democratic Societies (New York: Paragon House, 1992), pp. 57-74; Weller, Alternate Civilities, pp. 26-27.

15 Jonathan Schonsheck, "Rudeness, Rasp, and Repudiation," in Christine T. Sistare, ed., Civility and Its Discontents: Essays on Civic Virtue, Toleration, and Cultural Fragmentation (Lawrence: University of Kansas Press, 2004), p. 169.

16 Walzer, "Civility and Civic Virtue," p. 602; see also Edward Shils 1997a, "Ideology and Civility," in Steven Grosby, ed., The Virtue of Civility: Selected Essays on Liberalism, Tradition, and Civil Society (Indianapolis: Liberty Fund, 1997a), p. 49.

17 McGregor, "Civility, Civic Virtue, and Citizenship,” p. 26.

18 Both are outside individuals' private space and world.

19 Phrase from Ferdinand Mount, "Civility and Good Manners," Encounter vol. XLI, no. 1 (July 1973), pp. 31-43, cited in Shils, "Virtue of," p. 12.

20 Shils, "Civility and Civil Society," pp. 71-72.

21 See Sun Yatsen describing Chinese society as "a plate of loose sand" and the goals of the New Life Movement to "civilize" the common people. 
subjects of an authoritarian regime. Making "Taiwan" a meaningful unit to its inhabitants strengthens its democracy from the grassroots level. This paper will document these transitions, explain how they took place and identify the factors which helped bring them about.

Few direct measurements of civil behaviour are available, however, it is manifestly apparent to residents of and long-term researchers in Taiwan that as Taiwan's democratization and civil society noticeably deepened the level of civility improved. By no means is everyone civil all the time; indeed, there are still plenty of breaches of civility and public morality, from corruption in politics and business to those whose style is loutish behaviour, ${ }^{22}$ to mundane discourtesy and thoughtlessness. However, the overall improvement is palpable. Whereas in the past it was civil behaviour that was noticeable, it is now the breaches thereof which attract attention. Put simply, the public no longer passively accepts uncivil behaviour as they once did, and reprimanding offenders is not unusual. However, because there is little systematic data which directly measure these changes in behaviour and attitudes, the paper will largely rely on social indicators and observations to argue the case.

\section{Civility in Pre-Modern China?}

Some might argue that a notion of civility was developed in Chinese society over 2000 years ago in the Confucian classics, which contain rules of deportment regarding how men ${ }^{23}$ should treat each other. According to this tradition, all were educable in both letters and correct behaviour, the difference between a "gentleman" and a rustic being whether one behaved properly. However, these were "rules" (guiju) rather than "manners" (limao), regulations on how to defer to superiors in a society in which few were equals. Thus, they were status markers rather than displays of mutual respect. Moreover, they were mainly for the literate elite; they did not filter far down into society, and they applied to relations within one's circle of familiarity, not to society in general. According to Fukuzawa Y kichi and affirmed by Liang Qichao, in traditional Chinese society, emphasis was placed largely on "private virtue" ( side), the aim of which was to benefit the individual and his narrow circle rather than society as a whole. ${ }^{24}$ Furthermore, although the masses had their own standards of interpersonal conduct, pre-modern Chinese society was rampant with status inequalities. Proper behaviour from status inferiors to status superiors was often based on tacitly coerced deference.

22 For example, the so-called Taike.

23 The "sexist" noun is intentional; women had only domestic, and no social, roles.

24 Ruoshui Chen states that public virtue (gongde) is not limited to individuals' relationships with society for their personal benefit but extends to benefit all" [ Gonggong yishi yu Zhongguo wenhua (Public Consciousness and Chinese Culture)] (Taipei: Lianjing, 2005), p. 9. 
A related characteristic of pre-modern Chinese society was particularism..$^{25}$ Members of particularistic groups enjoyed solidarity and mutual assistance, but outside such groups there was competition, sometimes violent, for scarce goods. A consequence of particularism is that it divides the world into "us" (jiziren) and "them." The latter may be local competitors or strangers, neither of whom could be on a par with one's own people. Richard Wilson argues that particularism is reflected in Chinese child socialization patterns, which limit the extension of moral equivalence to members of the family and other particularistic groups with whom one affiliates. He observes that "[i]n societies where right thinking and conduct rigidly define group membership [such as Chinese society], individuals who are outside this realm of group orientation are often regarded as of lower moral worth on this account." ${ }^{26}$

\section{The Creation of Civility}

For civility to exist in a society the following conditions must be met. First, people must trust one another and trust that civility will be met with civility, not with rudeness or being taken advantage of. Fair play must be the operative modus vivendi. Second, people must have a sense of personal and material security. Lack of the former is antithetical to trust; lack of the latter is likely to produce zero-sum competition which will erode trust. ${ }^{27}$

Civility can exist under a variety of conditions. It can be found in "moral economies," communities in which there are high levels of reciprocity as a form of social insurance, where people help each other thinking that they may need help from others at some future date. ${ }^{28}$ Such communities are generally small-scale, homogeneous face communities. A larger-scale example was the nineteenth-century English working class, which enjoyed enhanced solidarity because of its class consciousness. ${ }^{29}$

However, in complex societies, those with differences in income, education, occupation, religion and ethnicity such that neither homogeneity nor opposition to another group can explain civility, we must look for other conditions which can create or nurture it. At the level of social interaction, some level of solidarity is necessary. This is unlikely to occur if:

25 See Fei Xiaotong, Xiangtu Zhongguo [Rural China] (Shanghai: Guancha She, 1948), p. 287, especially his notion of "graded interpersonal relationships" ( chaxu geju), i.e., differential treatment of others based on the closeness of the relationship.

26 Richard W. Wilson, "Moral Behavior in Chinese Society: A Theoretical Perspective," in Richard W. Wilson, Sidney L. Greenblatt and Amy Auerbacher Wilson, eds., Moral Behavior in Chinese Society (NY: Praeger, 1981), pp. 11-12.

27 Amélie Oksenberg Rorty, "From Decency to Civility by Way of Economics: First Let's Eat and Then Talk of Right and Wrong," Social Research vol. 64, no. 1 (1997), p. 113.

${ }_{28}$ James C. Scott, Weapons of the Weak: Everyday Forms of Peasant Resistance (New Haven: Yale University Press, 1976), pp. 40-44, 167-169.

29 E. P. Thompson, The Making of the English Working Class (Harmondsworth: Penguin, 1968), pp. 456-469. 
- there is a police state, especially if it has numerous undercover agents spying on the domestic population; ${ }^{30}$

- people feel that society is unjust or government unfair-democracy, while not a "necessary" condition, is important in this regard;

- they feel threatened, especially physically, by crime; or

- there are ethnic or religious rifts in society which create out-groups "undeserving" of civil treatment.

In contrast, civility in social interaction will likely be enhanced if people have positive feelings toward others and are relatively satisfied with their society. This can be assisted by:

- people or groups showing concern for others, e.g., through philanthropy, which can create a virtuous cycle;

- governments which are not oppressive and generally meet citizen needs and are regarded as efficient, responsive, honest, fair and concerned with improving society (which can increase satisfaction with government and with life in general);

- the development of a culture of obedience to road rules and courtesy to other drivers (the existence of which encourages its continuance); and

- an overall contentment with life and with the outlook for the future, which should reduce feelings of zero-sum competition with others and enhance camaraderie.

Similarly, civility in terms of caring for the physical public realm is improved by:

- people being sufficiently well off that they are no longer willing to sacrifice either the natural or the built environment for economic growth;

- the existence of public places which people enjoy visiting such as parks, malls, nature reserves, scenic drives, mountain trails, water recreation areas or hot springs;

- public education campaigns including reminders not to litter, public waste disposal facilities, and enforcement of anti-littering/defacing regulations; and

- something like a "no broken windows" policy, to keep public spaces clean and in good repair.

Few of these conditions held when the above-mentioned public morality campaign was on in the 1960s, but conditions have changed, and civility became increasingly manifest in the 1990s.

30 Susan Spülbeck, "Anti-Semitism and Fear of the Public Sphere in a Post-Totalitarian Society East Germany," in Chris Hann and Elizabeth Dunn, eds., Civil Society: Challenging Western Models (London and New York: Routledge, 1996), pp. 64-78. 


\section{What Has Changed?}

To begin with, traffic is less chaotic. Speeding is much less common. Drivers are less aggressive, more likely to give way to other drivers, less likely to cut dangerously into another's lane, generally content not to try to squeeze a fourth lane onto a road marked for only three. Stopping for pedestrians in zebra-crossings and obeying traffic signals and signs is the norm. Traffic deaths were a steady 7500 per year from 1990-1995 but declined to 4300 per year by $2003 .^{31}$

People now queue. Smoking on buses, in lifts, and in designated nosmoking areas is rare. Moreover, even where people are allowed to smoke, e.g., in private restaurant rooms, most hold their burning cigarette behind them to avoid subjecting non-smokers to their smoke. Betel chewers by and large spit into cups, not onto the street. The streets are cleaner, as are other public spaces such as public parks. The new Mass Rapid Transit (MRT) subway in Taipei is a model of exemplary public behaviour: passengers generally queue, let others off before trying to squeeze on, frequently give their seats to the elderly, the physically impaired, children or women with children or carrying packages, and they scrupulously obey the no-smoking, food, beverages or chewing gum rules. ${ }^{32}$

Treatment of strangers has markedly improved. Whether directed at someone on the street asking directions, at customers in shops or clients of service industries, treatment is generally genial and helpful. This is especially noticeable at government offices where friendly, helpful service contrasts markedly with the condescending, bureaucratic demeanour of the past. This improved treatment also reflects the entire range of interaction between citizens and government in that local governments now engage in community consultation, seeking and accepting public opinion.

Volunteer service has also become increasingly commonplace. According to Interior Ministry data, there was a 123 percent increase in the number of volunteers between 1996 and 2005; moreover, in 2003, 14.5 percent of the population, one in seven, was a volunteer, almost double the 1994 level. ${ }^{33} \mathrm{~A}$ substantial number of volunteers work in government offices, while others serve in public and private hospitals, non-profit service provider facilities, airports, the Taipei MRT, museums, historical sights and other places where visitors may be unfamiliar with procedures, facilities or information.

Volunteer service is also common for Taiwan's Christian and indigenous religious groups, which contribute greatly to the country's social, welfare

\footnotetext{
31 Min-huei Hsu, "In Taiwan, Taking Action on Road Safety Made a Difference," British Medical Journal 331 (2005), p. 904.

32 Anru Lee, "Subways as a Space of Cultural Intimacy: The Mass Rapid Transit Systems in Taipei, Taiwan," The China Journal, issue 58 (2007), p. 47.

33 Yifen Wang, "Baodao zui zhide mang de shi: zhiyuan fuwu" [The Most Worthwhile Busy-ness in Taiwan: Volunteer Service] Yuanjian Zazhi [Global Views Magazine] vol. 241 (July 2006), pp. 190-92.
} 
and relief services. Noteworthy among these groups are those representing a new, socially active Buddhism. Tzu-chi Gongde Hui (Compassionate Relief Merit Society), the largest such organization, has over 70,000 volunteers who assist in its three hospitals, administer relief to the poor, engage in rubbish recycling, and do a host of other work. Foguangshan, Dharma Drum and Lingjiushan also provide volunteers for similar social as well as religious purposes. ${ }^{34}$

Taiwan citizens donate generously to philanthropic causes. In 2004, 5.35 million donors (about one-quarter of the population) donated NT $\$ 42.7$ billion, an average of almost NT $\$ 8000$ per donor. ${ }^{35}$ This works out to NT\$ 2656 per capita, about US $\$ 81$ or 62 Euros, placing Taiwan midway among European countries, between Finland and Austria. ${ }^{36}$

\section{Immediate Forces for Change}

The establishment of democracy and a strong civil society have greatly assisted the development of civility in Taiwan. Democratization was hindered for a long time, first by the authoritarianism of the Japanese colonial government and then by Kuomintang state corporatist policy which, especially prior to President Chiang Kai-shek's death in 1975, placed all legal organizations under state-level umbrella bodies of the regime. Under his son and successor, President Chiang Ching-kuo, the government began to relax its control, making it possible for opposition groups to find room to manoeuvre. Toward the end of the 1970s, the dangwai, a non-Kuomintang group of politicians, ${ }^{37}$ began to organize and contest elections, leading to a democratization process beginning in the late 1980s. An autonomous civil society had begun to develop a few years earlier as demonstrations and protests increased, in particular over environmental, labour and economic issues. Women's groups, religious groups and a consumer movement also arose. Formal democratization began when Chiang Ching-kuo lifted martial law in 1987 and allowed the formation of opposition parties. The pace of democratization accelerated following his death in 1988 when the legislature revised the Civil Assemblies Law in 1989, allowing citizens to establish autonomous organizations. From slightly over 6000 groups in 1989, the number increased to over 18,000 in 2001. ${ }^{38}$

These groups have been significant in expanding participation in Taiwan's civil society. A third of them focus on social welfare and charity, with others

\footnotetext{
34 For example, chanting for the recently deceased (zhunian).

35 "PhilNews," available online from <http://www.npo.org.tw/PhilNews/Layout. asp?NEWSID=6964>, cited 29 March 2005.

36 "Answers," available online from <www.minhac.es/ief/Publicaciones/Revistas/Hacienda\%20 Publica/165/165_charitable.pdf>, cited 29 March 2005.

37 Prior to the lifting of martial law, it was illegal to organize new political parties.

38 Yun Fan, "Taiwan: No Civil Society, No Democracy," in Muthiah Alagappa, ed., Civil Society and Political Change in Asia: Expanding and Contracting Democratic Space (Stanford: Stanford University Press, 2004), p. 176.
} 
dedicated to business, education, culture and sports. One type of group actively promotes local communities by organizing school and adult projects to research community history and customs. Through writings, exhibitions, performances and local festivals, they involve a much wider public, creating community identity and enhancing social networks and social capital. Adult education colleges have made similar contributions through projects focussed on local area needs, e.g., one in a rural community which worked to renew agriculture. These groups attract a wide variety of students, from those with little education to some with advanced degrees. ${ }^{39}$ Since the 1990 s the government has supported and encouraged community projects and community identity.

Another important change is the more egalitarian interaction between government and citizen. For most in Taiwan, the main contact with government is at a sub-municipal or county level. ${ }^{40}$ These District Offices (quxiang gongsuo) used to be small and rudimentary. Clients stood in line, often for long periods, waiting to be served, and when their turn came, especially if they were poor or working class, they often received condescending, officious treatment. That changed when Chen Shui-bian became Taipei mayor in 1994. He had a self-declared mission to make the public service truly serve the public, and, as the first directly elected mayor since $1967,{ }^{41}$ he knew his job depended on voter support. ${ }^{42}$ Despite some changes of emphasis by his successor, the District Offices are now radically different from the past.

The old counters were replaced by desks so that the client and the public servant sit facing each other at the same level. Department heads and their staff are trained to treat visitors as customers and to offer them tea, a standard way to welcome guests to one's home..$^{43}$ The public servant's name is readily visible to the visitor to promote more personal interaction. Rather than having to stand in line, visitors take a number and wait their turn, sitting on chairs or sofas. Magazines, newspapers, tables for preparing paperwork, photocopy machines, reading glasses and even facilities for children to play are available. Volunteers assist visitors by directing them to the proper window to transact their business, helping them fill out forms or rendering other assistance. Persons who complain to or have an outstanding issue with a public servant over the phone receive a written response with the responsible employee's name and contact number so that follow-up is easier and more convenient. Procedures have been simplified so that visitors can complete

39 Fan, "Taiwan," pp. 181-85.

40 These are multi-functional offices frequently visited by ordinary citizens.

41 Kao Yushu was elected mayor in 1964. In 1967, Taipei became a provincial-level municipality (yuanxiashi) under which the mayor was appointed. Kao then served an additional five years.

42 He lost his re-election bid but received more votes than when initially elected.

43 Previously, clients often brought gifts to ensure timely transaction of their business. 
their business more quickly, and public servants even visit less mobile citizens in their homes.

Some department heads initially resisted these changes, in part fearing they would undermine their authority, but most were converted when they found that civility on their part was reciprocated by client civility and gratitude. To ensure continued compliance with these work rules and good service to visitors, departments continuously monitor service provision, periodically asking visitors to fill out questionnaires rating the service. Employees receive merits or demerits on their record based on their treatment of clients. ${ }^{44}$

Another area in which Chen initiated improvements was driver behaviour. Taiwan has never been short of laws and road rules. Prior to democratization, however, enforcement was sporadic, with strict campaigns followed by long periods of laxity. The campaign under Chen was sustained. To improve traffic flow, he ordered that all available officers be on duty during the morning and evening rush hours and that they ensure that traffic laws were enforced, in particular those governing parking, red lights, pedestrian crosswalks and turning at intersections. Public servants were sent to check whether officers were doing their jobs properly and to report those who were not. ${ }^{45}$ Long-term taxi drivers agreed that strict police enforcement of traffic rules, including fining offending drivers, was effective in changing driver behaviour. Gradually, obedience became habitual, and both compliance with road rules and traffic flow, while by no means perfect, improved significantly. ${ }^{46}$

The Taipei City Government's service reforms quickly spread to other government organs in Taipei and other cities and townships in Taiwan, and even attracted a Japanese study team, which came to observe the changes.

\section{Indirect Forces for Change}

Several forces have indirectly facilitated the development of civility. Changes in the traditional world view noted above by Wilson have expanded people's orientations from parochial outlooks and particularistic relationships to a more universalist view of others and a more inclusive view of society. "Taiwan identity" is now widespread. Taiwan has democratized, civil society has

44 Deputy manager, interview by author, MP3 recording, Nangang, Taiwan, 4 December 2006.

45 Research officer, 1989-2001, Research, Development and Evaluation Division, Executive Yuan, interview by author, MP3 recording, Muzha, Taiwan, 18 October 2006.

46 The 1997 campaign to get motorcycle riders to wear helmets is another example of using punitive measures to secure compliance which then becomes habitual. From June 1, all riders were required to wear helmets. Media outlets greeted the announcement with derision, proclaiming it unenforceable. On the first weekend police issued over 30,000 citations in Taipei alone. Motorcycle helmets are now widely accepted. In his article "Subways as a Space of Intimacy," Lee also states that when the Taipei MRT opened, despite libertarian-style criticism, monitors ensured compliance with rules, initially informing offenders of rule breaches then issuing fines. Monitoring is now greatly reduced, and breaches of rules are rare. 
expanded, and changes in the social and physical environment have made citizens feel more relaxed and secure, creating social conditions conducive to this transition to civility.

Taiwan is now a relatively prosperous society with an estimated 2005 per capita GDP of US $\$ 26,700,{ }^{47}$ (87 percent that of Japan). Since the 1980 s, people have shown a willingness to trade incremental income for leisure, and governments have provided funding for public recreational facilities and for local community functions, historical research and other activities aimed at creating community identity and amity. Furthermore, with a Gini coefficient of 0.339 (2006), ${ }^{48}$ income is distributed relatively equally, ${ }^{49}$ although less so than in the 1980s. An important manifestation of this relative equality is the home ownership rate, close to 85 percent in $1999 .{ }^{50}$

In addition, the general population is better educated than twenty years ago. It is more middle-class in both consumption and attitudinal terms. Moreover, many citizens have lived abroad for extended periods. Large numbers of university graduates have studied overseas since the 1950s, especially in the United States and Japan. During the 1960s and 1970s, most remained abroad after graduating for economic or political reasons. However, as the Taiwan economy improved through the 1970s, many finished their graduate studies and returned to Taiwan to pursue their careers. There were also some who, after working overseas for ten to twenty years and rising up the corporate ladder, returned to work in Taiwan's growing high-tech sector. While living abroad, returnees absorbed a different perspective of public morality and practice.

Taiwan's democratization has meant that people no longer fear their government, moreover, they expect more outputs, i.e., public outputs rather than patronage, and to have some choice in those outputs. As mentioned above, the bureaucracy has changed, and so have other government organs. While Taiwan was still ruled by an authoritarian government, officials and police were essentially unchecked and could act as they pleased toward the public. But since democratization, with people able to talk directly to their

47 CIA World Handbook 2006, available online at <http://www.cia.gov/cia/publications/ factbook/rankorder/2004rank.html>, accessed 7 Oct 2006.

48 Tseng Wei-chen, "Why would Taiwan try to emulate Singapore?" Taipei Times, available online at <http://www.taipeitimes.com/News/editorials/archives/2008/01/26/2003398949>, accessed 11 August 2008.

49 Morawetz et al. found self-rated happiness negatively correlated with income distribution. While civility differs from happiness, it follows that unhappy individuals would be less likely to be civil. See David Morawetz, Ety Atia, Gabi Bin-Nun,Lazaros Felous, Yuda Gariplerden, Ella Harris, Sami Soustiel, George Tombros and Yossi Zarfaty, "Income Distribution and Self-Rated Happiness: Some Empirical Evidence,” The Economic Journal, vol. 87, no. 347 (1977), pp. 511-522.

50 Accounting and Statistics, ROC, The 1999 Survey Report on Family Income and Expenditures in the Taiwan Area, Republic of China (Taipei: Directorate-General of Budget, Executive Yuan), available online at <http://www.gio.gov.tw/info/taiwan-story/economy/edown/chart/chart-4.htm>, cited 22 Nov 2005 . 
local representatives or their offices or air grievances on talk-back radio, they regard politicians and public servants as more responsive, friendly and obliging, and police as helpful rather than threatening.

This has resulted in more populist politics, one manifestation being changes in the image and style of political leaders. Chiang Kai-shek's image, as exemplified by the short film that accompanied the singing of the national anthem before movie showings, was one of a military man (often dressed in his uniform), aloof, distant, and wielding commanding power without a hint of softness or closeness to the people. Successor Chiang Ching-kuo's image was much gentler, more often seen in a jacket rather than a suit coat, sometimes talking to ordinary Taiwanese farmers working in their fields. Lee Teng-hui, whose regime brought in many of the fundamental changes which democratized Taiwan, had a very familiar style reflecting his democratizing role. Chen Shui-bian has a very folksy style, making a virtue of his very humble roots, and he refers to himself in his heavily Taiwanese-accented Mandarin by a familiar nickname, "A-bian," rather than "I." As mayors of the two largest cities (Taipei and Kaohsiung), Ma Ying-jeou and Hsieh Chang-ting ${ }^{51}$ frequently appeared on TV news reports singing and dancing with various constituency groups. Moreover, a ubiquitous self-characterization of candidates running in the 2006 elections was "love."

Politically, Taiwan has become more like a welfare state, with citizens demanding more of government and protesting loudly when entitlements are reduced or abolished. Moreover, local politicians have taken up issues of popular local concern, for example the "sweep out four colours" campaigns by Chen Shui-bian when he was Taipei mayor: "black" (electronic gaming machines aimed at the young), "white" (curb juvenile delinquency), "red" (improve traffic conditions) and "yellow" (banish the sex industry). These campaigns received high levels of public support. By contrast, and showing that people are not shy to oust politicians whose efforts they deem insufficient, Wu Dun-yi lost the Kaohsiung mayoralty to Hsieh Chang-ting in part because voters felt that he did too little to solve Kaohsiung's water problem..$^{52}$ Aside from improving water quality, one Hsieh initiative was to clean up Kaohsiung's Love River and improve the area along a stretch of its banks, creating a pleasant public and "civil" space where people can walk, hear live music, drink coffee and take boat rides.

Public facilities have improved, creating a positive image of public space and an identity with the local area. There are more public use facilities such as malls, pubs, coffee shops, parks, performing arts venues, interesting

\footnotetext{
51 Hsieh was Kaohsiung mayor from 1998 to 2004, then a Cabinet official and Democratic Progressive Party presidential candidate in 2008; Ma, KMT, was Taipei mayor from 1998-2006 and won the presidency in 2008.

52 During Wu's term, Kaohsiung's water supply was so polluted by local industry that people resorted to buying water for drinking and cooking.
} 
restaurants with newly developed cuisines, even all-night bookstores where people can read before deciding to buy. ${ }^{53}$ There are also public events such as fun runs, art exhibitions and outdoor photo displays. Two initially political monuments in Taipei, the Sun Yat-sen and Chiang Kai-shek Memorials, ${ }^{54}$ have evolved from political symbols of an authoritarian state to become public parks where people go for exercise or relaxing strolls and as events venues.

There are also more outdoor recreational areas such as national parks, bike paths, hiking trails and scenic spots. Moreover, people have cars and more leisure time, enabling them to visit tourist and recreation areas. In addition, family-run inns ( minsu), where holiday makers can find inexpensive accommodation, have recently increased greatly in number, making holidays more affordable. This increase in outdoor recreation is accompanied by a growing sense of environmentalism, ${ }^{55}$ and enjoying the natural environment is Taiwan's single most preferred recreational activity. ${ }^{56}$ These sentiments demonstrate a sense of stakeholdership and a reason to feel pride in Taiwan, creating incentives to maintain such spaces and facilities.

Taiwan's ward ( $l i)$ system has also seen changes aimed at enhancing a sense of community. Chinese governments have tried to organize communities for well over a millennium, but these have always been top-down efforts aimed at control. Such efforts continued in postwar Taiwan through the ward system, the primary functions of which were communicating government information, ensuring social and political order, disaster relief, and government-organized community development schemes to provide amenities. While this system may have been helpful to the government, it made few grass-roots improvements. The system was top-down, and urban ward headships (lizhang) were often low-level sinecures for retired Mainlander soldiers.

More recently, however, many ward heads are well educated and achieve their positions by winning genuinely contested elections. Many of them work to improve their local communities, and over the last decade there have been government grants available for projects such as local history or festivals to solidify community identity. There are also spontaneous grass-roots community organizations which want no government links and prefer to do everything on their own. Some find it difficult to overcome the inertia of urban disinterest and inaction, but others have succeeded well beyond their original aims. ${ }^{57}$

53 Residential exteriors and surroundings have also been improved.

54 On May 19, 2007 the CKS Memorial was renamed Taiwan Democracy Memorial Hall. Thanks to Bruce Jacobs for that information.

55 Many protest movements in the 1980 s and 1990 s were over environmental problems, and there is now a much greater awareness of the importance of the environment in creating a pleasant living environment.

56 Yang-chih $\mathrm{Fu}$, personal communication, based on preliminary analysis of a social change survey results

57 Virginia Sheng, "Here Comes the Neighbourhood," Free China Review (May 1995), pp. 4-29. 
Self-definition movements have arisen over the past two decades, including women's, Hakka and Taiwan consciousness movements. Taiwanese consciousness, a largely but not exclusively $\mathrm{Hoklo}^{58}$ movement, simmered beneath the surface through the post-1945 period of repression of local identity by the KMT government, but it burst onto the scene after democratization began with huge numbers of publications on Taiwanese history and customs and the promotion of Taiwanese in addition to, if not to the exclusion of, Chinese identity. This is reflected in Taiwan's politics, where the main division is between those who seek independence and those who see Taiwan as part of China and desire reunification at some point in the future.

In the last several years, Taiwan identity has expanded to include Taiwan aborigines, a group once so disparaged that they were referred to simply as huan-a, "savages." ${ }^{59}$ Today, Taipei's Jieshou Boulevard has been renamed Ketagelan after an aboriginal tribe, and a word meaning "welcome" in one aboriginal language is now used by the Taiwan Tourist Bureau in its advertising. ${ }^{60}$ Moreover, there is government support to preserve aboriginal languages and cultures.

The women's movement was initiated by professional and academic women and, strongly influenced by Western feminist concerns, it took robust stances on a variety of political and ideological issues. More recently the movement has attracted women from the middle levels of society whose interests focus on equal opportunity, establishing women's refuges and protecting and assisting women in disadvantaged positions such as divorcées, single mothers and foreign brides.

The Hakka movement is a reaction to the Hakka being a minority Taiwanese group that has historically felt oppressed by the numerically and recently politically dominant Hoklo speakers. Government authorities formally recognize the Hakka as a separate group and have granted a license to a Hakka TV channel. Political candidates now try to learn the Hakka language, and parties make high-profile appointments of Hakka candidates. While this movement increases Hakka identity, it also reduces or eliminates feelings of deprivation or discrimination by the numerically superior Hoklo or the politically more powerful Mainlanders, thus helping ameliorate antagonistic divisions in society.

58 The four groups are Hoklo, Hakka, Mainlanders and Aborigines; they respectively make up 75, 10, 14 and 1 percent of Taiwan's population.

59 Having no generic word for aboriginal groups, following the Han Chinese, they even referred to themselves in this way; see Melissa J. Brown, Is Taiwan Chinese?: The Impact of Culture, Power, and Migration on Changing Identities (Berkeley, Los Angeles, London: University of California Press, 2004), pp. 68-69.

60 The street running to the front of the Presidential Building is now known as Ketagelan Boulevard; the greeting on tourist ads is "Naruwan." 
Such movements, comprised of sectors of the population which have historically been pitted against other sectors, may be seen as divisive. However, as mentioned above, they also broaden individuals' spheres of acquaintances beyond small, particularistic groups, and they create bonds of morality with many "strangers" who share the same identity. Moreover, these movements help equalize formerly subordinate groups with society's dominant groups, thus empowering them. By contrast to the pre-democracy period, one could argue that there is no longer a dominant group in Taiwan. Instead, there are many groups which, although competing with each other, do so freely and openly, and individuals are often cross-linked with persons in other groups.

Another important movement was based on concerns for the local or broader environment. Beginning in the 1980s, a variety of environmental protests sprang up. Some were very large and became cause célèbres; examples include opposition to Taiwan Power installing a nuclear power plant, DuPont building a chemical plant, or Formosa Plastics constructing a naphtha cracker. Most were local in that they were protests aimed against industries which polluted the local water, air or tranquillity. Although some were NIMBY protests, a nationwide environmental movement grew out of them, making people aware of the environmental costs of Taiwan's economic growth ${ }^{61}$ and broadening their perspectives to Taiwan as a whole.

Finally, socially engaged Buddhism contributes to universalist perspectives. First, at the conceptual level, Buddhism's primary ethical principle is compassion, often explicitly extended to all life but certainly to all humankind. Second, at a practical level, this ethic is not empty rhetoric but is practiced by what the Buddhists do, creating positive models of philanthropy and concern. As mentioned above, all the groups engage, at least indirectly, in disaster relief..$^{62}$ Four are involved in social welfare projects assisting the poor, orphans, the elderly, children in single-parent households and others. Three are engaged in environmental clean-up, recycling and programmes and education aimed at reducing resource use, and one promotes organic farming. Several have periodic blood donation drives, Tzu-chi has a bone marrow bank, and both Foguangshan and Tzu-chi provide medical services through hospitals and clinics. Especially in Tzu-chi, there is a high and visible level of volunteerism, and it has even added a requirement to obey traffic regulations to the five basic Buddhist commandments.

\footnotetext{
${ }_{61}$ On the environmental movement, see Hsin-huang Hsiao, Women zhiyou yige Taiwan: fan wuran shengtaibao yu huanjing yundong [We Have Only One Taiwan: The Anti-Pollution, Ecological Conservation and Environment Movement] (Taipei: Yuanshen 1987).

62 Leaders of the smallest group, Fuzhi, feel it is too small to contribute directly, but it donates funds to groups which have relief programmes.
} 
Third, because these activities are well-known to the public through both their own and the public media, they set positive examples of universalism and compassion to others. That there are over one million persons in Taiwan who donate monthly to Tzu-chi alone, enabling it to raise hundreds of millions of US dollars annually, demonstrates the respect people feel toward socially engaged Buddhism and what it does for society.

Fourth, the Buddhist groups are a uniting force in society. Although there are still some tensions between the various ethnicities in Taiwan, in Buddhism whether one is Hoklo, Hakka, Mainlander or Aborigine makes no difference. Five of the groups were established by Mainlanders, one by a Taiwanese, yet the ethnic composition of all groups reflects their proportions of Taiwan's population as a whole. Members thus choose a group on the basis of its own teachings and emphasis, not on the ethnicity of the founder. At worship services, older members sometimes sit through sermons by monastics speaking a language that they do not understand. The attitude that "we are one in Buddhism" reflects the general ecumenical attitude expressed toward other Buddhist groups and in some groups toward other religions as well: there are 84,000 dharma paths, and each has to find the one most suitable for her or himself.

Finally, the Buddhist groups, in the manner of other organizations and movements mentioned above, broaden social capital networks and horizons, putting individuals into contact with a diversity of others they would otherwise be unlikely to know. Whether the link is causal or associational, a 2004 survey shows that members of the three largest groups are more likely than the general public to participate in social groups other than the Buddhist group of which they were members $(p<0.001)$, donate money to a social group $(p<0.01)$, volunteer for a social group $(\mathrm{p}<0.05)$, and participate in an environmental protection group or activity $(\mathrm{p}<0.001) .{ }^{63}$

\section{Divisions in the Population}

The most common image of Taiwan on Western television-legislators abusing, fighting with and even throwing things at each other-would hardly support the contention of this article, that Taiwan is developing a society marked by increasing civility. In addition, there were some very disorderly protests over the results of the 2004 presidential election and several months of demonstrations in Taipei in the latter half of 2006, including one which disrupted the president's address at the national day celebration in front of foreign dignitaries. Although such unruly behaviour began in the 1980s, it

63 David C. Schak, "Socially-Engaged Buddhism in Taiwan and its Contributions to Civil Society," in Mutsu Hsu, Jinhua Chen and Lori Meeks, eds., Development and Practice of Humanitarian Buddhism: Interdisciplinary Perspectives (Hualien: Tzuchi University Press, 2007), pp. 220-223. 
has increased markedly in the past several years, and it represents some genuine divisions in Taiwan.

The essential split is between Mainlanders, those whose forebears, or themselves, came from Mainland China in the latter half of the 1940s, and Taiwanese, those whose ancestors arrived prior to Japanese colonization in 1895. Mainlanders overwhelmingly support the KMT and its allies-the "blue camp" - which advocates eventual reunification of Taiwan and China. ${ }^{64}$ Although some Taiwanese also support the blue camp, the majority oppose reunification and support some form of de facto or de jure independence, a position advocated by the other major political force, the Democratic Progressive Party (DPP) and its allies-the "green camp." ${ }^{65}$ Tensions have risen in the past several years because the incumbent president, Chen Shuibian of the DPP, has in the eyes of many made several moves toward Taiwan independence and, although economic performance has been below that prior to the pre-dot-com crash in 2000, reform has been scant because the executive and legislative branches of government, controlled by different parties, are at a stalemate and have refused to compromise or cooperate.

However, these divisions have not visibly affected the general level of civility. Taxi drivers complained privately about the extra crowding of the already very busy streets in central Taipei where the 2006 demonstrators were, but they took no action. Pedestrians walking by might smile at or greet demonstrators if they agreed with them or practice civil inattention if they did not, but they did not argue with them. Why? First, people in Taiwan generally accept others' freedom of conscience as part of democracy. Second, in public places people are simply people. They are not immediately identified as Mainlander, Hakka, KMT or independence supporter. They are simply fellow residents of Taiwan who are deserving of the normal courtesies that one gives to another-in terms used above, they practice tolerance. That the 2008 election went off peacefully and its results were greeted with civility reinforces this.

This civility is exemplified by an incident related by a friend which took place on New Year's Eve, 2006, after the years of political division and months of demonstrations as described above.

My wife and I were at the Taipei Forest Park to watch the fireworks from 101 [a skyscraper]. As midnight approached, more and more people had joined the crowd at the rear. Being toward the front, we had a good view, but there were trees which, together with people standing in front, blocked the view of people further back. As midnight approached, a group of youths in the rear yelled in unison, "Would those in front please

64 Former Taipei mayor and KMT 2008 presidential candidate, Ma Ying-jeou, has stated that reunification will take place only after China democratizes.

65 The colours of these camps represent the colours of the flags of the KMT and DPP respectively. 
sit down." Nothing happened. They shouted again, and still nothing happened. I began to worry that things could become quite unpleasant. The youths shouted for a third time, and a few people yelled back, "If I sit down and those in front still stand I won't be able to see." Again those in back shouted their request, and, suddenly, the whole crowd, almost in unison sat down, and everyone got a view of the fireworks.

Although anecdotal, that this happened to a senior researcher at the Academia Sinica Institute of Sociology who related it as representative of present-day civility enhances its credibility.

\section{Conclusions}

To conclude, since the 1990s, Taiwan has become a democratic society and is becoming an increasingly civil one. Pre-democratic governments contributed to it by overseeing the conditions which brought about a rise from a poor to a prosperous, highly educated and sophisticated population in two generations. Post-democratic governments did so by systematically enforcing laws which brought about more order in society, encouraging community development and consciousness, developing domestic tourism, reforming its procedures to serve its populace rather than rule them and, most essentially, empowering the citizenry. They eschewed top-down campaigns, which had been used with the public morality issue in the 1960s. Some aspects of civility, especially driver behaviour, are less closely adhered to in the smaller cities and the rural areas than in the larger cities, where residents are more sophisticated and well off, but the overall difference from the past is palpable for both residents and long-term visitors.

Still, as Putnam argues, ${ }^{66}$ civility can be lost if people's attitudes and behaviour change, and there are some potential dangers in Taiwan. There are complaints about poor social order, though none of the fifty-plus persons, mostly women, I've interviewed in various parts of Taiwan over the past few years expressed fear of being out alone at night. Although Taiwan is still a relatively egalitarian society, inequality is rising; moreover, one increasingly hears complaints about a deteriorating economy and falling living standards. On closer questioning, people often say that this perception is based not on absolute decreases but on their no longer getting regular salary increases as they did through the 1990s. There is a real problem of structural unemployment which affects over-forty males who have lost jobs because so many businesses have moved to China. This problem will be very difficult to solve, and coupled with a weakening of family ties, might result in the older generation being left to fend for itself.

${ }^{66}$ Putnam, Bowling Alone, pp. 77-78. 
These problems and perceptions, especially when coupled with frequent threats from Beijing, the somewhat dysfunctional political system, and Taiwan's sensationalist, politically biased and dishonest media, which pumps out a constant stream of scandal and social discord, could lead to a loss of confidence in Taiwan society and generate a more sauve qui peut attitude. In that event, Taiwan's civility would most likely decline. But for the time being, Taiwan, the first Chinese democracy, ${ }^{67}$ is both a civil society and a society with civility.

Griffith University, Queensland, Australia, December 2008

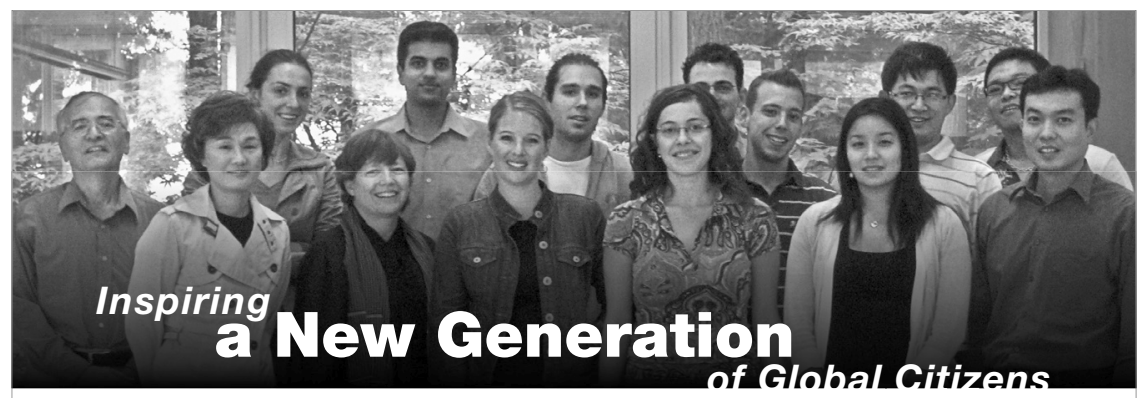

MASTER OF ARTS-ASIA PACIFIC POLICY STUDIES (MAPPS) PROGRAM

The University of British Columbia has earned a reputation for innovation and excellence in both teaching and research, and the Institute of Asian Research, whose faculty includes some of Canada's most renowned Asia specialists, is Canada's leading research authority on the study of Asia.

The MAPPS program provides advanced training in research and analysis on policy issues relevant to the Asia Pacific region to graduate students preparing for positions in government departments, non-profit organizations and private sector enterprises, and as preparation for academic doctoral programs. Small seminars and practical internships distinguish the MAPPS program.

For more information, visit http://www.iar.ubc.ca/programs/mapps/index.html.
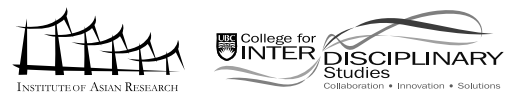

67 Bruce Gilley, "Taiwan's Democratic Transition: A Model for China,” in Bruce Gilley and Larry Diamond, eds., Political Change in China: Comparisons with Taiwan (Boulder \& London: Lynne Reinner, 2008), pp. 219-233. 